\title{
A proteção jurídica das pesquisadoras no Brasil: o desafio da mulher na ciência
}

\author{
The Legal Protection Of Female Researchers In Brazil: \\ The Challenge Of Women In Science
}

Julia Stefanello Pires

PUC/PR e FATEC/PR

LETÍCIA SCHEIDT GREGIANIN

UFGD

MARIANA LiRA DE Freitas

PUC/PR e UTFPR

RESUmo Segundo o estudo "Gender in the Global Research Landscape: Analysis of research performance through a gender lens across 20 years", o qual fez uma análise da pesquisa sob a ótica de gênero e apontou uma crescente participação feminina na vida acadêmica, apesar de ocuparem um espaço cada vez maior na academia, as mulheres ainda enfrentam obstáculos causados pela desigualdade de gênero que as impedem ou, no mínimo, dificultam uma ascensão na carreira de pesquisa. O objetivo do artigo é apresentar as dificuldades e a ausência de políticas específicas que considerem as questões de gênero na vida acadêmica, o que acaba refletindo na inclusão de mulheres na ciência. $\mathrm{O}$ estudo se deu por meio de uma pesquisa bibliográfica e documental, sendo analisados estudos específicos sobre o assunto, assim como leis e regulamentos da Coordenação de Aperfeiçoamento de Pessoal de Nível Superior (CAPES) e de alguns dos principais Programas de Pós-graduação do Brasil.

Palavras-chave: Gênero; CAPES; Pós-graduação; Pesquisa.

ABSTRACT According to the study "Gender in the Global Research Landscape: Analysis of research performance through a gender lens across 20 years", which made an analysis of the research from a gender perspective and pointed out an increasing female participation in academic life. Despite occupying an increasing space in the academy, women still face obstacles caused by gender inequality, which prevent them, or at least hinder, a rise in the research career. The objective of the article is to present the difficulties and the absence of specific policies that consider gender issues in academic life, which ends up reflecting on the inclusion of women in science. The study will take place through a bibliographic and documentary research, with specific studies on the subject being analyzed, as well as laws 
and regulations of the Coordination for the Improvement of Higher Education Personnel (CAPES) and some of the main Graduate Programs in Brazil.

Keywords: GeNDER; CAPES; POSTGRADUATE STUDIES; SEARCH.

\section{INTRODUÇÃO}

Apesar de muitos avanços nas conquistas feministas na ocupação de espaços políticos e sociais, a desigualdade de gênero ainda é uma realidade que cria obstáculos na vida das mulheres. A divisão de trabalhos domésticos, a carga invisível sobre a mulher e questões de liberdade sexual e reprodutividade ainda são pautas que geram grandes impactos no desenvolvimento pessoal e profissional de mulheres pelo mundo inteiro, porém, o presente trabalho se limitará a discutir a situação das brasileiras.

Embora tais desigualdades possam ser debatidas por diversas perspectivas, o artigo se concentra nos problemas específicos enfrentados pelas mulheres que seguem a carreira acadêmica, partindo de uma análise das normas da Coordenação de Aperfeiçoamento de Pessoal de Nível Superior (CAPES) para programas de pós-graduação e avaliação de professores e professoras (MARTINS, 2003, p. 294-309).

Ainda, essa análise parte do pressuposto geral de questões de gênero, sendo que as desigualdades se tornam ainda mais gritantes quando são colocados em discussão outros fatores de opressão como classe social e questões raciais (BUTLER, 2008, p. 25). No entanto, apesar de se compreender a importância do debate, o trabalho não irá se aprofundar nesses pontos, os quais merecem um estudo mais específico.

Há um evidente crescimento na ocupação das mulheres em cargos de pesquisa, segundo estudo "Gender in the Global Research Landscape: Analysis of research performance through a gender lens across 20 years", o qual fez uma análise da pesquisa sob a ótica de gênero. No Brasil, entre 1996 e 2000, as mulheres representavam 38\% dos pesquisadores, sendo que entre 2011 e 2015 já ocupavam 49\% do setor. Dos países analisados, apenas Portugal apresenta igual taxa de pesquisadoras, sendo que os demais países registram uma menor proporção de mulheres na pesquisa (ALVES apud ELSEVIER, 2017).

No entanto, apesar de ocuparem um espaço cada vez maior na academia, as mulheres ainda enfrentam obstáculos causados pela desigualdade de gênero, os quais as impedem ou, no mínimo, dificultam a ascensão delas na carreira de pesquisa. Isso se dá especialmente porque as políticas pensadas para a promoção da pesquisa no Brasil habitualmente ignoram as questões de gênero (CABRAL, 2005), como se pretende demonstrar nos tópicos a seguir.

Nesse ponto, há de se considerar que as questões de gênero se cruzam com outros tipos de opressão como a homossexualidade, transgeneridade, raça e desigualdade social, fatores que, em conjunto ao gênero, devem ser discutidos para uma efetiva promoção das mulheres na pesquisa. Porém, apesar de compreender a importância da discussão dessas opressões, o trabalho se limitará a discutir questões especificamente relativas ao gênero, abrindo espaço para que nesta discussão se acrescentem outros debates em futuros estudos.

O objetivo do artigo é apresentar as dificuldades e a ausência de políticas específicas que considerem as questões de gênero na vida acadêmica, o que acaba refletindo na inclusão de mulheres na ciência, ou na dificuldade delas em seguir e manter uma carreira na área. Para 
atingir esse propósito, o trabalho foi dividido em três partes: em um primeiro momento, é abordada a carga de trabalho invisível da mulher brasileira, a fim de demonstrar-se em dados a desigualdade de gênero na divisão de responsabilidades e trabalhos domésticos.

A partir dessa desigualdade, são expostas as normas e as políticas da CAPES, ou a ausência delas, no que diz respeito às questões de gênero e, por fim, são apresentadas iniciativas e boas práticas dentro da pesquisa no Brasil que buscam diminuir as desigualdades de gênero e efetivar a inclusão das mulheres na vida acadêmica.

\section{DESIGUALdAde de GÊNERO: A CARGA DE TRABALHO INVISÍVEL DA MULHER BRASILEIRA}

A integração da mulher nas esferas sociais, historicamente vistas como essencialmente masculinas, deu-se de forma muito particularizada, uma vez que não se faz possível conceber o processo histórico da evolução da mulher, sobretudo na educação e no mercado de trabalho, como fruto de um paradigma igualitário e unificador. Assim, a incorporação da mulher nessas duas esferas deu-se por meio da gradual modificação de barreiras nitidamente impostas pelo sistema social e capital vinculado à forte concepção de exclusão feminina e superioridade masculina (SCOTT, 1991, p. 444).

No mundo ocidental o gênero sempre foi colocado como questão basilar dentro das possibilidades de inserção do indivíduo no mercado de trabalho e na educação. Tradicionalmente, a mulher era posta à margem essencialmente por especificidades biológicas, uma vez que tem a capacidade natural de realizar o trabalho reprodutivo, enquanto o homem, por sua vez, geraria aquele tido como produtivo, ou seja, em que haveria a troca, enquanto o da mulher dava-se pela reprodução da vida material que não agregava valor imediato à esfera econômica (BARROSO, 1982, p. 54).

Assim, para um entendimento sociológico mais aprofundado, torna-se essencial segregar a sociedade industrializada em esferas pública e privada, sendo a primeira aquela em que o mercado de trabalho está inserido e a segunda aquela tida como ambiente doméstico, no qual a mulher viria a exercer seu trabalho reprodutivo e doméstico. Esse entendimento faz-se fundamental para a compreensão de que as diferenciações entre as esferas pública e privada eram essenciais para que a mulher se inserisse especificamente no trabalho reprodutivo que, ao gerar valor econômico insignificante comparado ao trabalho masculino, imediatamente estigmatizava-a na posição de dependente e subordinada (COUTINHO, 1994, p. 42). Ainda, conforme Coutinho:

[...] as mulheres, portanto, donas de casa, passam a ser trabalhadoras que nunca vão conhecer os benefícios que aos poucos a sociedade capitalista nascente vai outorgando a outros trabalhadores [...] Sua dedicação exclusiva ao trabalho doméstico impede e dificulta a participação autônoma das mulheres nos espaços públicos, que ficam restritos aos homens, levando-as a uma marginalidade social (COUTINHO, 1994, p. 42).

A emancipação da mulher, desse modo, embora indispensável, deu-se de forma gradual e com o objetivo imediato de suprir necessidades do mundo capitalista e necessaria- 
mente patriarcal, uma vez que, ao começar a ocupar espaços públicos e realizar o trabalho com retorno produtivo, a mulher tinha uma posição extremamente limitada, uma vez que a ocupação feminina se deu sobretudo pela necessidade de força produtiva que reivindicasse menor valor de retorno (LAGRAVE, 1991, p. 510). Assim, a própria ideia de emancipação feminina por meio do trabalho não podia ser vista como genuína, uma vez que a manutenção da estrutura econômica somente permitia uma liberdade exclusivamente formal.

A dificuldade no acesso à educação deu-se concomitantemente, visto que a imersão falsamente intrínseca da mulher na esfera privada implicava certa negligência à forma como a educação era oferecida e exposta a ela. Dessa maneira, estando distante tanto do mercado trabalhista quanto da educação formal, o papel da mulher como subalterna e submissa foi colocado como evidente, o que posteriormente contribuiu para que, ainda que inserida no trabalho, a mulher fosse admitida nos postos mais precários e com as condições salariais mais defasadas, uma vez que a racionalização capitalista distinguia de forma clara o trabalho daquele que era e não era qualificado, e não havia possibilidade de efetiva qualificação sem estudo (BARROSO, 1982, p. 92).

Além disso, o discurso de inferioridade da mulher era bastante difundido e necessariamente atribuído ao seu sexo biológico e, até meados do século XIX, ele foi fundamental para que a educação, fortemente embasada pelo Positivismo, fosse tida como privilégio essencialmente masculino justamente pelo pressuposto da insuficiência intelectual feminina, derivada de concepções etiológicas nitidamente individualistas que permitiam assunções bastante acríticas e estereotipadas sobre a mulher (RAPKIEWICZ, 1998, p. 170).

Com a divisão sexual do trabalho, no século $\mathrm{XX}$, as argumentações positivistas de base supostamente biológica perpetuaram a discriminação feminina no mercado e na educação e, assim, a sociedade deixou de ser dividida somente em esferas pública e privada, mas também em feminina e masculina, uma vez que, embora introduzida no trabalho externo, a mulher ainda era vista como fisicamente e, sobretudo, intelectualmente inferior (BUTLER, 2008, p. 30). Posto isso, a divisão sexual do espaço de trabalho acarretou na consequente divisão dos processos de formação profissional, criando estereótipos à mulher justificados de formas facilmente questionáveis. Conforme Rapkiewicz:

[...] apesar da participação cada vez maior das mulheres na esfera dito produ-
tiva, o senso comum lhes atribui uma certa incompetência na área científica e
tecnológica. Esses domínios, e em particular a tecnologia, são considerados
coisas de homem. [...] Se ainda hoje o senso comum considera, em certa me-
dida, o domínio tecnológico como sendo masculino, o constante aumento da
participação feminina em certas profissões demonstra que a origem do proble-
ma não é natural. As diferenças entre os sexos são constituídas em diferentes
esferas como a família, a escola e o mercado de trabalho. [...] A informática
parece oferecer maiores oportunidade às mulheres do que outros ramos, como
a engenharia, por exemplo (RAPKIEWICZ, 1998, p. 171).

Essa separação das esferas trabalhistas deu-se pela atribuição de diferentes tarefas e responsabilidades aos respectivos gêneros pelo motivo único de seu sexo biológico e, com isso, essa divisão acabou sendo responsável pela primeira integração da mulher no magistério, uma vez que essas eram vistas como educadoras, trabalho que supostamente exigiria 
menor capacitação física e intelectual (LAGRAVE, 1991, p. 521). Tal ideia vincula-se ao estereótipo do cuidado maternal e da educação básica, os quais a mulher, de acordo com o pensamento dominantemente masculino, poderia exercer sem muitas dificuldades.

Inserida de forma mais veemente na educação, a mulher passou a ser a principal responsável pela perpetuação dos moldes e ideais capitalistas, vindo a educar aqueles que, futuramente, ingressariam no mercado de trabalho de forma a gerar valor produtivo. Todavia, isso não quer dizer que ela começou a ser vista como intelectualmente superior ou até mesmo igual, e sim como um produto subordinado responsável por repassar os moldes ideológicos de uma sociedade que girava de forma maquinal. Embora profissionalmente admitidas, as mulheres não produziam conhecimento de forma efetiva, pertencendo a uma esfera pública, mas com características privadas quase que reprodutivas (YANNOULAS, 2011, p. 271).

Embora a docência não tenha sido um elemento inicialmente emancipatório à mulher, ela foi responsável por sua primeira efetiva inserção dentro da educação, o que, posteriormente e de forma muito gradual, permitiu uma modificação sistemática que a tirou da posição de mera repassadora dos moldes patriarcais vigentes (ALMEIDA, 1998, p. 60).

Todavia, não se pode dizer que essa mudança se deu de forma total, uma vez que a premissa básica de inserção da mulher na educação continuou dando-se embasada na ideia de condicionadora às práticas morais não desviantes. Além disso, depreendia-se que, quanto mais elevado fosse o grau de ensino, menor era a participação feminina dentro do corpo docente. Assim, nos cargos com menor remuneração e maior requisição de qualificação intelectual, a mulher não se via presente, e o prestígio continuava sendo essencialmente masculino (ALMEIDA, 1998, p. 63).

No entanto, com o magistério a libertação da mulher passou, gradativamente, a ser vista como material e não unicamente formal, como era dentro do mercado de trabalho maquinário. Lentamente, a educação como trabalho passou a inserir a mulher de forma mais visível em uma dinâmica que era necessariamente masculina e veementemente patriarcal (ALMEIDA, 1998, p. 64).

Assim, a introdução feminina na educação se realizou de forma progressiva, e sua imersão cada vez mais frequente em todas as esferas do mercado de trabalho permitiu sua entrada em ambientes que até então eram masculinos, como nos cursos superiores e no campo da pesquisa científica, por exemplo, que virão a ser o objeto mais aprofundado deste estudo. Com essa análise histórica, faz-se possível compreender que, de forma lenta e paulatina, a mulher conseguiu inserir-se na esfera da educação, a qual, até então, era unicamente masculina, e isso permitiu seu posterior ingresso na ciência e na pesquisa.

Embora recente, as últimas décadas mostram de forma clara o aumento exponencial da presença feminina dentro das universidades e dos centros de pesquisa (ELSEVIER, 2017), no entanto, os avanços são pontuais e ainda existem diversas barreiras sociais que impedem a completa inserção da mulher dentro do ambiente acadêmico, uma vez que a própria formação ideológica social faz-se responsável pela perpetuação das desigualdades relativas ao gênero, o que acaba por limitar a capacitação feminina em diversos aspectos, uma vez que até mesmo o ambiente acadêmico permite e impõe uma divisão sexual dos espaços de conhecimento. 
Contudo, as maiores possibilidades de escolaridade qualitativa fizeram-se fundamentais para que o campo científico começasse a comportar um número maior de mulheres, lentamente quebrando o conceito de que esses seriam espaços predominantemente masculinos (COUTINHO, 1994, p. 45). No entanto, a grande problemática nessa questão é que, mesmo em situações de predominância feminina, as políticas adotadas na metodologia e na própria efetivação da pesquisa continuam sendo essencialmente masculinas, pouco abordando a mulher e questões intrínsecas a ela que deveriam ser levadas em consideração, como a carga de trabalho invisível socialmente imposta a ela de forma histórica, ou mesmo direitos sexuais e reprodutivos. Ou seja, permite-se que as mulheres ocupem tais espaços, desde que se encaixe nos padrões determinados pelos moldes masculinos.

A construção do espaço doméstico como esfera privada da sociedade consubstancia-se no entendimento de que a mulher é completamente responsável pela adoção de papéis tripartidos de esposa, dona de casa e mãe. Historicamente colocada na posição de esposa-companheira, a mulher teve seu papel social há muito traçado como responsável pela manutenção do lar, do bem-estar do marido e dos filhos e, embora a emancipação feminina em muito tenha ajudado nessas questões, esse arquétipo continua bastante solidificado no imaginário social (COUTINHO, 1994, p. 43). Dessa forma, a mulher inserida no mercado de trabalho e no ambiente de pesquisa, além de assumir papéis dentro desses espaços, também carrega a invisível carga de responsabilização pela preservação da esfera privada.

É inviável analisar a ocupação das mulheres no campo científico sem compreender todas as diferenças biológicas e sociais que a permeiam, uma vez que a divisão sexual dos espaços é um apontamento histórico existente muito antes da própria inserção da mulher no mercado de trabalho. Ao ser responsável pelo trabalho reprodutivo material, ou seja, tendo a capacidade biológica de engravidar, a mulher sempre foi colocada como responsável pela perpetuação da sociedade e pela manutenção e amparo da esfera privada, sendo esse o alicerce fundamental da própria estrutura patriarcal e capitalista (YANNOULAS, 2011, p. 270).

Embora a inserção da mulher na educação tenha sido um ato evidentemente emancipador, ele não foi suficiente para dividir as tarefas da esfera privada com o homem, o que se dá de forma bastante pontual, uma vez que, socialmente, a mulher ainda é vista como protetora do lar, mesmo quando inserida no mercado de trabalho e no campo de pesquisa.

Mesmo com um olhar mais aprofundado às desigualdades e com uma relativa diminuição dessas, a forma como o trabalho científico e docente observa a mulher ainda é carregado de fortes estereótipos e preconceitos, uma vez que seu desempenho acadêmico continua sendo visto como inferior ao do homem quando concomitante à dedicação à família e aos afazeres domésticos. Por isso, o gênero não pode ser entendido tão somente como sexo biológico, e sim como um elemento constitutivo das relações sociais que permite a atribuição de significado à hierarquização, à divisão do trabalho e às relações de poder (ARAUJO, 2005, p. 41).

Assim, é por meio da compreensão do gênero como determinante das relações sociais que se faz possível compreender como a ciência historicamente foi e continua sendo vista como um espaço masculinizado em que, mesmo com a inserção das mulheres, não se faz possível ver com certa abrangência políticas adotadas especificamente para elas dentro do meio acadêmico. 
Atualmente, mesmo com a ocupação maciça das mulheres nos cursos superiores e no campo da pesquisa científica (MENEZES, 2016, p. 88), as desigualdades que constantemente as desfavorecem continuam sendo evidentes, o que pode perceber-se pela ausência de políticas protetivas às mulheres que engravidam ou adotam dentro do período da pesquisa científica; o reduzido número de mulheres na posição de educadoras em cursos superiores; a discriminação no campo da pesquisa e as dificuldades de acesso em cursos que não sejam essencialmente de licenciatura, entre outros (FERRAND, 1994, p. 359).

Com essa compreensão mais aprofundada da posição social da mulher devido ao estabelecimento das relações de gênero e com o entendimento da divisão e hierarquização das esferas públicas e privadas, faz-se possível entender que os fatores biológicos, embora evidentes, nunca foram ou devem ser suficientes para justificar a discrepância e desvalorização da mulher na ciência, uma vez que as relações históricas embasadas em relações patriarcais de poder traçaram para a mulher uma imagem não somente de esposa, companheira e mãe, mas também de naturalmente inaptas à pesquisa e a liderança, desvalorizando tanto sua carga invisível de trabalho na esfera privada quanto paradoxalmente invalidando sua capacitação intelectual e física na esfera pública.

\section{CAPES E AS QUESTÕES DE GÊNERO: OS OBSTÁCULOS NA VIDA DA PESQUISADORA}

A inclusão do sistema misto de educação no século XX, em que mulheres e homens passaram a ocupar o mesmo espaço no ensino básico, trouxe um grande avanço às lutas feministas, permitindo o desaparecimento de barreiras formais no acesso à educação (MENEZES, 2016, p. 63). Com o passar do tempo, a expansão do ensino foi globalizada e a mulher foi inserida no sistema acadêmico de forma mais contundente, embora seu espaço intelectual fosse bastante limitado a algumas áreas de ensino.

Ao longo dos anos, o Brasil estabeleceu um dos principais ensinos de pós-graduação da América-Latina (MARTINS, 2003, p. 03), despontando como um dos primeiros países que atingiram igualdade de gênero no maior nível educacional existente. Desde 2004, as mulheres não são mais minorias em doutorados, contudo, nota-se que ainda existe uma constante desvalorização da produção acadêmica feminina.

As universidades surgiram como principal impulsionador de produções acadêmicas hodiernamente; a ciência emergiu como primordial no desenvolvimento educacional e tecnológico de uma sociedade (MARTINS, 2003). A academia, por sua vez, mostrou-se um instrumento de disseminação e obtenção de conhecimento objetivando modificações e melhorias de um corpo social.

No início dos anos 50, no Brasil, foi observada a necessidade de inserção de políticas públicas que visassem o desenvolvimento econômico e social do país e, com isso, nasceu a CAPES - Coordenação de Aperfeiçoamento de Pessoal de Nível Superior e o CNPq Conselho Nacional de Desenvolvimento Científico e Tecnológico, instituições de fomento da pesquisa brasileiras (MARTINS, 2003). Enquanto o CNPq tornou-se uma das principais instituições de incentivo à pesquisa no Brasil, conforme preceitua Martins (2003), o objetivo principal da CAPES

[...] era garantir a existência de pessoal especializado em quantidade e quali- 
dade suficientes, para atender às necessidades dos empreendimentos públicos e privados que visavam ao desenvolvimento econômico e social do país naquele momento. (MARTINS, 2003, p. 04-05).

A CAPES, a qual será tratada de forma mais aprofundada neste estudo, atualmente figura como principal agência de fomento da pesquisa de pós-graduação do país, conferindo bolsas a pesquisadores, realizando avaliação da pós-graduação stricto sensu; divulgando a produção científica; promovendo a cooperação científica internacional, a indução e o fomento da formação inicial e continuada de professores para a educação básica nos formatos presencial e a distância ${ }^{1}$.

Contudo, ainda existe uma constante desvalorização da produção acadêmica feminina. Menezes (2016), em sua dissertação, apresenta dados referentes à concessão de bolsas de incentivo à pesquisa nos anos de 2014 e 2015, divididos por sexo e, apesar das mulheres serem maioria nas bolsas de iniciação científica ( $59 \%$ contra $41 \%$ das concessões a homens), a situação é oposta conforme o grau de titulação vai aumentando. A pesquisa aponta que, além do número de bolsas que exigem maior titulação ser majoritariamente destinada aos homens, essa realidade não teve alteração no decorrer dos anos. Menezes (2016, p. 67-68) aduz: "No caso das bolsas de pesquisa, que exigem maior titulação, a disparidade fica em torno de 64\% de concessões para os homens contra $36 \%$ de bolsas oferecidas às mulheres".

Esses números trazem à tona uma realidade enfrentada pelas pesquisadoras do país: ao passo que as instituições de fomento vêm crescendo de forma exponencial, a qualidade e o alcance do ensino de pós-graduação da mulher ainda são invisibilizados nessa seara. A evidenciação dessa situação, todavia, não pode ser vista como ocasional, uma vez que demonstra o resultado lógico da divisão sexual do trabalho e do estudo incentivada e promovida desde os primeiros momentos da industrialização e da ascensão do viés de mundo capitalista (RAPKIEWICZ, 1998, p. 171).

Assim como o gênero, a ciência também é um instrumento social e histórico e, por isso, mesmo atualmente integrando mulheres em seu corpo, não traz espaço suficiente para que seu paradigma androcêntrico predominante seja eliminado, embora as tentativas de escondê-lo sejam constantes (FERRAND, 1994, p.361). Em síntese, entende-se que não basta somente integrar a mulher à ciência: a ciência precisa comportar a mulher e existir, também, de acordo com suas especificidades.

No decorrer das últimas décadas, percebe-se com bastante clareza os avanços referentes à inserção da mulher no campo da pesquisa científica. $\mathrm{Na}$ atualidade, a porcentagem predominante de alunos matriculados em cursos de graduação é feminina (INEP, 2019) mas, da mesma forma, a predominância do reconhecimento científico continua sendo essencialmente masculina, criando o questionamento de qual seria o exato momento em que o crescimento exponencial no número de mulheres pesquisadoras, estudantes e docentes dá lugar à visibilidade quase que unicamente masculina.

Essa resposta dá-se de forma bastante simples, uma vez que pode ser encontrada dentro da própria concepção moderna de gênero. Conforme Judith Butler (2008),

Tal informação pode ser acessada no site da CAPES. Disponível em https://www.capes.gov.br/historia-e-missao. Acesso em 26 de julho de 2020. 
[...] o gênero não deve ser meramente concebido como a inscrição cultural de significado num sexo previamente dado (uma concepção jurídica); tem de designar também o aparato mesmo de produção mediante o qual os próprios sexos são estabelecidos (BUTLER, 2008, p. 25).

Assim, além de construção social, o gênero também deve ser reconhecido como produtor e reprodutor de relações de poder que distinguem e segregam os corpos de acordo com sexo, gênero e sexualidade (LAQUEUR, 2001, p. 17), e essa segregação é a principal responsável pelas porcentagens educacionais de classificação de sexo da forma como são apresentadas.

A ciência não pode ser vista como neutra, uma vez que ela é produzida e reproduzida para homens da mesma forma que a distribuição de papéis relativas ao gênero formador é produtor de hierarquizações sociais. Dessa forma, embora bastante inserida na educação formal, a mulher continua sendo constantemente excluída da ciência, a qual nunca foi programada para ela, já que engloba essencialmente a perspectiva social daqueles que a criaram.

$\mathrm{Na}$ vida acadêmica se observa que diversos valores que, historicamente, são atribuídos a homens, passam a ser pré-requisitos para o ingresso na pesquisa científica, e no momento que a mulher se mostra desprovida desses elementos valorativos, ela é imediatamente excluída sob o argumento de incapacidade. Ao abordar o signo "valor", o pensamento humano imediatamente é redirecionado à perspectiva de hierarquização social, o que não é a abordagem deste estudo e, por isso, nesse momento, compreende-se "valor" como a caracterização masculina em tudo aquilo que é requisitado nos mais diversos campos de relações de poder que, historicamente, somente podem ser alcançados por homens (FERRAND, 1994, p. 362).

Por exemplo, ao ser institucionalizado o papel da mulher como protetora da esfera privada da sociedade (COUTINHO, 1994, p. 40), ela imediatamente passa a ser excluída da pesquisa científica por não poder dedicar seu tempo exclusivamente a si, da mesma forma que, ao ser a reprodutora natural da vida humana, o próprio campo da pesquisa exclui a mulher dentro de suas políticas internas, por não promover sistemas de proteção e resguardo a mulher que, por esses fatores, não pode dedicar à ciência o mesmo montante de tempo que um homem poderia, sendo historicamente colocado como integrante da esfera pública (ALMEIDA, 1998, p. 65). Nenhum desses pontos é intrinsecamente valorativo, já que se tratam de questões construídas socialmente para reproduzir a imagem de superioridade universal e estrutural masculina, o que se mostra cada vez mais inconsistente.

Assim, o entendimento que coloca o gênero e a ciência como paralelos dentro da cultura e da própria história pressupõe sua compreensão imediata relacionada ao poder e à forma como esse é distribuído. Dessa forma, entende-se que o fato de a quantidade de mulheres que seguem a pesquisa científica não ter aumentado de forma significativa, ao passo que o número de graduandas cresce de forma exponencial (MENEZES, 2016), certamente precisa ser relacionado à distribuição dos papéis de poder dentro de uma sociedade de valores predominantemente masculinos.

O constante fenômeno de precarização das condições de trabalho contribui para o afastamento do homem da carreira científica, permitindo a aproximação da mulher que consegue unir o trabalho produtivo com o reprodutivo. Assim, embora nos últimos anos a 
participação da mulher tenha crescido de forma considerável nas universidades, tal crescimento continua limitado à segregação institucional já bastante histórica nos centros de ensino (FERRAND, 1994, p. 363).

Dessa forma, embora a luta feminista tenha contribuído de forma inegável à tomada de espaços masculinos por mulheres, faz-se possível compreender que as relações de poder continuam as mesmas, e que a própria história permitiu que a mulher fosse inserida nesse meio, mas sempre sob profunda segregação territorial (SCHIEBINGER, 2001, p. 77), tendo em vista a própria divisão sexual e de gênero dentro da pesquisa que institui determinados meios da educação como masculinos ou femininos, sendo aqueles de maior prestígio e remuneração, permitindo a perpetuação do estereótipo da mulher como incapaz e menos produtiva, quando comparada.

\section{A (IN)EXISTÊNCIA DE INICIATIVAS E bOAS PRÁTICAS PARA A INCLUSÃo DE GÊNERO DA MULHER PESQUISADORA}

O acesso das mulheres à educação fora do seio privado domiciliar foi um dos passos mais importantes na luta feminista. Segundo Bell Hooks (1952, p. 43), a produção acadêmica de mulheres reflete diretamente no avanço do pensamento feminista "quando exigiu respeito pelo trabalho acadêmico de mulheres, reconhecimento desse trabalho do passado e do presente e o fim dos preconceitos de gênero em currículos e na pedagogia". Portanto, valorizar a voz e o conhecimento produzido pela mulher é essencial para que ela ocupe seu lugar de direito na sociedade.

Hooks (1952, p. 43) reconhece a importância do pensamento feminista dentro da academia, contudo, suscita o problema da elitização do ensino. A autora denomina como "gueto acadêmico" uma pequena parte da população geralmente branca e de classes sociais mais altas que têm acesso aos estudos feministas. Cita a desradicalização do movimento, tornando-o apenas uma disciplina como qualquer outra, com enfoque específico no gênero. $\mathrm{O}$ ingresso de um maior número de mulheres à academia, nos cursos de graduação ou pós-graduação emerge como uma saída para a "academização" exagerada dos estudos feministas. Políticas públicas de inclusão de mulheres mães, negras e pobres manifesta-se como uma pauta essencial da luta feminista.

Em pesquisa recente da Parent in Science (2020), instituição que se dedica a discutir os efeitos da maternidade e paternidade na ciência, foi feito um levantamento com discentes de pós-graduação, pós-doutorado, docentes e pesquisadores acerca da produção acadêmica durante a pandemia de COVID-19. Segundo o levantamento, mulheres negras e mulheres brancas com filhos foram os grupos mais atingidos em termos de produtividade acadêmica, enquanto homens, principalmente sem filhos, tiveram a produtividade menos afetada.

Nota-se que as pesquisadoras com filhos que submeteram artigos científicos correspondem a 47,4\% do total, enquanto homens com filhos representam 65,3\%. A desigualdade acadêmica da mulher fica ainda mais evidente quando esses dados são relacionados de acordo com a idade dos filhos. Docentes mulheres com filhos de um a seis anos tiveram $28,8 \%$ dos artigos submetidos conforme planejado, já homens com filhos na mesma faixa etária tiveram 52,4\% de seus artigos submetidos, clarificando de forma bastante evidente 
os papéis atribuídos a cada um dos gêneros até mesmo dentro da esfera privada (PARENT IN SCIENCE, 2020).

As dificuldades e desigualdades de gênero, além disso, tem suas especificidades de áreas. Em uma pesquisa publicada no periódico de ciências exatas, Em Questão (2019), analisou-se a porcentagem de publicações de doutorandos e doutores por gênero e subárea, conforme tabela a seguir:

Tabela 1 - Porcentagem de publicações na amostra por gênero e subárea

\begin{tabular}{|c|c|c|}
\hline Áreas e subáreas & Homens & Mulheres \\
\hline Ciências Exatas e da Terra & $528.159(74,85 \%)$ & $177.464(25,15 \%)$ \\
\hline Astronomia & $17.241(84,72 \%)$ & $3.110(15,28 \%)$ \\
\hline Física & $186.488(84,65 \%)$ & $33.818(15,35 \%)$ \\
\hline Ciência da Computação & $69.595(82,09 \%)$ & $15.185(17,91 \%)$ \\
\hline Matemática & $53.154(80,66 \%)$ & $12.742(19,34 \%)$ \\
\hline Probabilidade & $45.663(77,35 \%)$ & $13.372(22,65 \%)$ \\
\hline Geociências & $77.318(75,26 \%)$ & $25.414(24,74 \%)$ \\
\hline Oceanografia & $19.874(68,13 \%)$ & $9.297(31,87 \%)$ \\
\hline Química & $149.536(64,30 \%)$ & $83.038(35,70 \%)$ \\
\hline
\end{tabular}

Fonte: Elaboração própria a partir dos dados de TUESTA, 2019.

O estudo concluiu que a produtividade de mulheres nas áreas supracitadas é estatisticamente menor do que sua participação, ou seja, embora as mulheres continuem sendo maioria dentro da academia, sua produtividade acaba sendo mais baixa do que a masculina, o que certamente não se dá por fatores de capacitação e muito menos por questões biológicas. Segundo Carla Cabral (2005, p. 02), a resposta a essa discrepância entre homens e mulheres nas ciências exatas se dá por meio dos mecanismos históricos e da socialização da mulher. A autora aduz que o afastamento histórico entre mulheres e o círculo criativo e de liderança de produção:

[...] limitou sua atuação fora da esfera privada da casa e foi, séculos após séculos, evidenciado pela sua ausência e condução em carreiras como a física, a química, a biologia, a matemática, a engenharia e, mais recentemente, a computação. Estas áreas desenvolveram-se ao sabor de valores considerados masculinos, como a certeza, a eficiência, o controle e a ordem. (CABRAL, 2005, p. 2).

Esses números evidenciam um cenário peculiar: ainda que as mulheres representem um número significativo dentro da academia, a produtividade delas acaba sendo afetada. Para compreender a diferença de produtividade, tanto nas áreas exatas quanto durante a pandemia de COVID-19 é de extrema importância suscitar a dupla jornada vivida pela mulher, anteriormente explanada diante do aprofundamento na compreensão das esferas públicas e privadas da sociedade industrializada e capitalista. 
Conforme já mencionado, existe uma significativa preocupação na falta de medidas protetivas às mulheres que se tornam mães no período da pesquisa científica. Nessa lógica, a Lei n. 13.536 (BRASIL, 2017), permite a prorrogação de prazos a pós-graduandas bolsistas e veda a suspensão das bolsas durante o período, o qual pode-se equiparar à uma licença-maternidade.

Nessa senda, o presente estudo procedeu a análise de cinco regulamentos gerais de Programas de Pós-Graduação de prestígio acadêmico no Brasil, todos vinculados às universidades públicas, sendo eles: Universidade de São Paulo (USP); Universidade de Campinas (UNICAMP); Universidade Federal do Rio de Janeiro (UFRJ); Universidade Federal de Minas Gerais (UFMG) e Universidade Federal do Rio Grande do Sul (UFRGS). Para critério de escolha, observou-se que tais instituições são consideradas as cinco melhores universidades do Brasil de 2019, segundo Ranking Universitário Folha (2020), o qual analisa a pesquisa, ensino, mercado, internacionalização e inovação de cada universidade.

O Regimento Geral da Pós-Graduação da USP (USP, 2020) dispõe expressamente acerca da licença-maternidade a todas estudantes dos programas vinculados à universidade. A UNESP (2019) apenas menciona o direito à licença-maternidade no Regulamento Geral, os prazos, procedimentos e protocolos ficam a critério de cada programa. A UFRJ (2020) e UFMG (2020) não abordam licença-maternidade em seus regulamentos, todavia, em pesquisa realizada nos sítios eletrônicos de cada instituição, foi constatada a existência da licença-maternidade apenas à bolsistas, o que significa que não bolsistas provavelmente não gozam da suspensão de prazos. O regulamento da UFRGS, por fim, não está disponível.

É válido ressaltar que a redação da lei supramencionada não abarca mulheres pósgraduandas sem bolsa. Nessa perspectiva, mulheres que se tornam mãe durante o período da pós-graduação em universidades como UFRJ e UFMG não são contempladas pela suspensão de prazos. Mães que inúmeras vezes precisam lidar com uma tripla jornada de pesquisadora e mãe dentro do mercado de trabalho. Ressalta-se, nesse ponto, que não se tratam apenas de obstáculos financeiros, mas também da necessidade de cumprir prazos da pós-graduação durante o puerpério.

Em pesquisa mencionada acerca da pandemia de COVID-19, a Parent in Science (2020) apresenta uma série de sugestões para melhoria da produtividade dentro do período abordado, como aumentar o prazo para submissão em editais de fomento; flexibilizar o prazo para prestação de contas e relatórios de projetos; elaborar editais específicos aos grupos mais atingidos, para evitar um aumento da disparidade de gênero e raça; programar os horários de reuniões, considerando o horário escolar no qual mães e pais devem dar suporte a seus filhos. No site da instituição (PARENT IN SCIENCE, 2020), inclusive, há um guia prático para organizadores de evento oferecerem recreação possibilitando maior participação de mães.

Os exemplos de boas práticas são poucos, primeiramente por serem quase inexistentes, e também pelo fato de que muitos editais saem do ar após o período de vigência, ficando difícil registrar as ações afirmativas adotadas. Nesse ponto, destacam-se algumas universidades públicas, como exemplo o caso da UNIPAMPA (2020), passaram a contabilizar o período de licença-maternidade na análise de currículo das pesquisadoras para distribuição de bolsas. 
Depreende-se, portanto que iniciativas estatais que buscam a inclusão de gênero na pesquisa são poucas e inexpressivas. No âmbito privado, destaca-se que o grupo empresarial L'Oréal Paris promove o programa "Para Mulheres na Ciência"2, em que são escolhidas pesquisadoras de diversas áreas a serem contempladas com uma bolsa-auxílio para desenvolverem suas pesquisas. Assim, observa-se que ações afirmativas de promoção da igualdade de gênero são movimentos isolados feitos por universidades, pessoas civis e até empresas que buscam equiparar essa desigualdade.

\section{CONSIDERAÇões FINAIS}

As conquistas femininas permitiram que as mulheres ocupassem, cada vez mais, lugares de direito na sociedade. O espaço acadêmico, onde se produz e se consome conhecimento, ciência e educação, é um local de extrema relevância e sua ocupação por minorias é urgente, posto que, assim, as particularidades e necessidades desses grupos possam ser analisadas, criando-se uma revolução no conhecimento a partir de seus membros outrora marginalizados.

Atualmente, como se mostrou acima, a presença das mulheres na ciência não está longe, em quantidade, em relação aos homens. No entanto, como analisado no trabalho, isso não significa que a qualidade de vida, de produção e de oportunidades dessas mulheres sejam iguais às de seus companheiros do sexo masculino.

A estrutura de produção da ciência continua sendo pensada por, para e sobre os homens, ignorando pontos como: necessidades particulares das mulheres como direitos de reprodução; combate ao preconceito e machismo nos ambientes de pesquisa, tendo em vista a disparidade de mulheres em posições de relevância e poder; assim como outros debates que devem acompanhar a questão de gênero: transgeneridade, raça e classe social, pontos que sequer são considerados no desenvolvimento atual das políticas de gênero na pesquisa.

No âmbito acadêmico, geralmente elitizado, apontar a existência de necessidades e particularidades de grupos oprimidos, por vezes é taxado como vitimização e busca de privilégios. Muitas mulheres escutam, em seus primeiros dias na pós-graduação, que aquele não é o momento de engravidar, ou que não deve se casar nova, para que isso não lhe atrapalhe na carreira acadêmica. Tais orientações, por seguro, não são passadas aos homens.

As escolhas pessoais das mulheres não deveriam ser de tamanha relevância a ponto de prejudicar ou retardar sua ascensão na carreira escolhida, o que ainda é muito comum na ciência. Outrossim, deve-se considerar que mulheres com filhos, pobres, negras ou transgênero, não só podem, como devem ocupar um espaço na produção de conhecimento. $\mathrm{E}$ como esse espaço não existe de bom grado, cabe a nós lutarmos por políticas de inclusão que abram os caminhos.

O desenvolvimento da ciência exige pluralidade de ideias, para que sejam mais claros os problemas a serem enfrentados, assim como mais variadas as soluções propostas. Para isso, o sistema de pesquisa e produção de conhecimento deve trabalhar para considerar as particularidades de grupos historicamente prejudicados, promovendo sua presença de fato e de direito dentro da ciência brasileira.

2 Conforme se observa no site do projeto "Para Mulheres na Ciência" (For Womens in Science). Disponível em: https://www.paramulheresnaciencia.com.br/. Acesso em 30 de julho de 2020. 


\section{REFERÊNCIAS}

ALMEIDA, Jane Soares de. Mulher e educação: a paixão pelo possível. São Paulo: Ed. UNESP, 1998.

ALVES, Daniela Maçaneiro. A mulher na ciência: desafios e perspectivas. In: Seminário de educação, conhecimento e processos educativos, 2., 2017, Florianópolis. Educação, Linguagem e Memória. Florianópolis: Ppge, 2017.

ARAUJO, Maria de Fátima. Diferença e igualdade nas relações de gênero: revisitando o debate. Psicol. clin. [online]. 2005, vol.17, n.2 [cited 2021-02-09], pp.41-52. Disponível em: http://www.scielo.br/scielo.php?script=sci arttext\&pid=S0103-56652005000200004. Acesso em 15 de julho de 2020.

BARROSO, Carmen. Mulher, sociedade e estado no Brasil. Brasília: Ed. Brasiliense, 1982.

BRASIL. Instituto Nacional de Estudos e Pesquisas Educacionais Anísio Teixeira (Inep). Censo da Educação Superior 2018: notas estatísticas. Brasília, 2019.

BRASIL. Presidência da República. Lei 13.536 de 15 de dezembro de 2017. Disponível em http://www.planalto.gov.br/ccivil 03/ ato2015-2018/2017/Lei/L13536.htm. Acesso em 20 de julho de 2020 .

BUTLER, Judith. Problemas de gênero: feminismo e subversão da identidade. Rio de Janeiro: Civilização Brasileira. 2008.pg 25.

CABRAL, Carla Giovanna. As mulheres nas escolas de engenharia brasileiras: história, educação e futuro. Cadernos de Gênero e Tecnologia, Curitiba, v. 1, n. 4 (2005). Disponível em https://periodicos.utfpr.edu.br/cgt/article/view/6139/3790. Acesso em 20 de julho de 2020.

COUTINHO, Maria Lúcia Rocha. Tecendo por trás dos panos: a mulher brasileira nas relações familiares. Rio de Janeiro: Rocco, 1994.

FERRAND, Michèle. A exclusão das mulheres da prática das ciências. Uma manifestação sutil da dominação masculina. Estudos Feministas, p. 358-367, 1994. Disponível em: https://periodicos.ufsc.br/index.php/ref/article/view/16169/0. Acesso em: 20 de julho de 2020 .

FOLHA DE S. PAULO. RUF - Ranking de Universidades 2019. Disponível em https://ruf. folha.uol.com.br/2019/ranking-de-universidades/principal/. Acesso em 15 de julho de 2020.

HOOKS, Bell. 1952. O feminismo é para todo mundo: políticas arrebatadoras. Tradução: Bhuvi Lianio - 10a ed. Rio de Janeiro: Rosa dos Tempos, 2020. 
LAGRAVE, Rose -Marie. Uma emancipação sob tutela. Educação e trabalho das mulheres no século XX. In: DUBY, Georges (Ed.). História das mulheres no Ocidente. Porto: Afrontamento, 1990-1991. $5 \mathrm{v}$.

LAQUEUR, Thomas. Inventando o sexo: corpo e gênero dos gregos a Freud. Rio de Janeiro: Relume Dumará, 2001.

MARTINS, C. B. A CAPES e a formação do sistema nacional de pós-graduação. In: CAPES 50 anos. Rio de Janeiro: FGV, 2003. p. 294-309.

MENEZES, Leopoldina Cachoeira. Gênero, ensino e pesquisa em matemática: um estudo de caso. Tese (doutorado) - Universidade Federal da Bahia, Faculdade de Filosofia e Ciências Humanas. Salvador, 2016. Disponível em https://repositorio.ufba.br/ri/handle/ ri/23853. Acesso em 15 de julho de 2020.

PARENT IN SCIENCE. Produtividade acadêmica durante a pandemia: efeitos de gênero, raça e parentalidade. 2020. Disponível em https://327b604e-5cf4-492b-910b-e35e2bc67511.filesusr.com/ugd/0b341b 81cd8390d0f94bfd8fcd17ee6f29bc0e.pdf?index=true. Acesso em 17 de julho de 2020.

RAPKIEWICZ, Clevi Helena. "Informática: domínio masculino”. In Cadernos Pagu: Gênero, tecnologia e ciência. Campinas, SP: Núcleo de Estudos de Gênero/UNICAMP, $n^{\circ}$ 10, 1998. p. 169-200.

SCHIEBINGER, Londa. O feminismo mudou a ciência?. São Paulo: EDUSC, 2001.

SCOTT, Joan W. A mulher trabalhadora. In DUBY, Georges (Ed.). História das mulheres no Ocidente. Porto: Afrontamento, 1990-1991. 4 v.

TUESTA, Esteban Fernandez et al. Análise da participação das mulheres na ciência: um estudo de caso da área de Ciências Exatas e da Terra no Brasil. Em Questão, Porto Alegre, v. 25, n. 1, p. 37-62, jan./abr. 2019. Disponível em https://seer.ufrgs.br/EmQuestao/article/ view/80193. Acesso em 19 de julho de 2020.

UFMG. RESOLUÇÃO COMPLEMENTAR No 02/2017, DE 04 DE JULHO DE 2017. Normas Gerais de Pós-Graduação da UFMG. Diponível em https:/www.ufmg.br/prpg/ wp-content/uploads/2017/07/2017 02 NormasGeraisPos-Graduacao.pdf. Acesso em 15 de julho de 2020 .

UFRJ - Pró Reitoria de Pós-Graduação e Pesquisa. FAPERJ amplia licença maternidade as pesquisadoras bolsistas. 23 de julho de 2018. Disponível em http://posgraduacao.ufrj. br/noticia/2076. Acesso em 15 de julho de 2020. 
UNESCO Brasil e a Academia Brasileira de Ciências, a L'Oréal Brasil. Para mulheres na ciência. Diponível em https://www.paramulheresnaciencia.com.br/. Acesso em 20 de julho de 2020.

UNESP. RESOLUÇÃO UNESP N 22, DE 13 DE MARÇO DE 2019. Dispõe sobre o Regimento Geral da Pós-graduação da Unesp. Disponível em: https://www2.unesp.br/portal\#!/propg/regimento-da-pos-graduacao/; Acessado em: 20 de agosto de 2020.

UNICAMP. CONSU-A-019/2020. Regimento Geral dos Programas de Pós-Graduação Stricto Sensu e dos Cursos Lato Sensu. 09 de junho de 2020. Disponível em https://www. pg.unicamp.br/mostra_norma.php?id_norma=21777. Acesso em 15 de julho de 2020.

UNIPAMPA. PDA 2020: Unipampa considera período de licença maternidade na análise do currículo das pesquisadoras. 24/03/2020. Diponível em https://unipampa.edu.br/ portal/pda-2020-unipampa-considera-periodo-de-licenca-maternidade-na-analise-do-curriculo-das-pesquisadoras. Acesso em 19 de julho de 2020.

UNIVERSIDADE FEDERAL DE MINAS GERAIS. Pró-Reitoria de Recursos Humanos Departamento de Administração de Pessoal. Licença à gestante. Disponível em https:// www.ufmg.br/prorh/wp-content/uploads/2019/08/leg.pdf. Acesso em 15 de julho de 2020.

USP. RESOLUÇÃO N 7493, DE 27 DE MARÇO DE 2018. Regimento da Pós Graduação da Universidade de São Paulo. Disponível em http://www.leginf.usp.br/?resolucao=resolucao-no-7493-de-27-de-marco-de-2018. Acesso em 15 de julho de 2020.

YANNOULAS, Silvia Cristina. Feminização ou feminilização? Apontamentos em torno de uma categoria. Temporalis, Brasília (DF), ano 11, n.22, jul./dez. 2011. Disponível em: https:// periodicos.ufes.br/temporalis/article/view/1368/1583. Acesso em: 23 de julho de 2020 .

\section{Julia Stefanello Pires}

Doutoranda em Direito Socioambiental pela PUC/PR. Mestra em Direitos Humanos e Fronteiras pela UFGD (2017). E-mail: juliastefanello@outlook.com.br

\section{Letícia SCHEIDT Gregianin}

UFGD. Graduanda em Direito pela Universidade Federal da Grande Dourados (UFGD).

\section{Mariana Lira de Freitas}

PUC/PR e UTFPR. Graduanda em Direito pela Pontifícia Universidade Católica do Paraná (PUC/PR). Graduanda em Letras pela Universidade Tecnológica Federal do Paraná (UTFPR)

Submetido em: 14-12-2020

Aceito em: 5-3-2021 